\title{
Técnicas Constructivas en las torres-ata- layas de Montefrío (Granada): La Torre de Las Cabrerizas
}

\section{Building techniques in the watchtowers of Montefrío (Granada): The tower of Las Cabrerizas}

\author{
Rafael J. Pedregosa Megías \\ Juan Miguel Rivera Groennou**
}

\begin{abstract}
RESUMEN
En este artículo se presentan parte de los resultados obtenidos tras las excavaciones arqueológicas realizadas en la Torre-atalaya nazarí de Las Cabrerizas ubicada en Montefrío, dentro del sector noroccidental del Reino Nazarí de Granada. Se analizan de forma sistemática las técnicas constructivas desde la perspectiva de la Arqueología de la Arquitectura y se estudian los morteros y enlucidos históricos a través de diferentes técnicas de laboratorio.
\end{abstract}

Palabras Clave: Torre-atalaya nazarí, Técnicas constructivas, Morteros, Enlucidos, SEM-EDX.

\section{INTRODUCCIÓN: LOCALIZACIÓN Y SITUA- CIÓN GEOGRÁFICA}

Las intervenciones arqueológicas realizadas sobre las torres atalayas de Montefrío se han desarrollado en varias fases, la que nos ocupa en la Torre-atalaya de las Cabrerizas tuvo lugar en la segunda quincena del mes de Julio de 2005 en el II Campo Nacional de Trabajo "Torres-Atalayas" de Montefrío (Granada) ${ }^{1}$, dentro de una de las iniciativas organizadas por el Instituto Andaluz de la Juventud (IAJ) - denominada Campos de Trabajo de Voluntariado Social-y el Ayuntamiento

\begin{abstract}
This article presents some of the results obtained from the archaeological excavations in the Cabrerizas Nasrid Watchtower in Montefrío, located within the north-west sector of the Nasrid Kingdom of Granada. It is studied the construction techniques from an Archaeology of Architecture perspective and analyzed historic mortars and plasters by different laboratory methods.
\end{abstract}

Key Words: Nasrid Watchtower, Construction techniques, Mortars, Plasters, SEM-EDX.

de esta localidad para la puesta en valor de dicho patrimonio.

Montefrío se ubica en la zona noroccidental de Granada en la comarca de los Montes Occidentales (BOSQUE MAUREL Y FERRER, 1999:233). El municipio se encuentra a $50 \mathrm{~km}$. de Granada en dirección NO, junto a la carretera A-335. Presenta una altitud media de $900 \mathrm{~m}$ y una extensión territorial de $254 \mathrm{~km}$.

La topografía se caracteriza por un relieve quebrado y montañoso, propia del sector central de las Cordilleras Béticas. Destacan forma-

* Universidad de Granada, rpedregosam@gmail.com.

** Departamento de Prehistoria y Arqueología, Universidad de Granada, juanmi2734@hotmail.com.

1 Queremos dar las gracias a los miembros del equipo que participó en el Campo de Trabajo, tanto al equipo director como a sus miembros, Jesús Bellón, Eva Celdrán, Natalia González, Antonio Martínez-Novillo, y por supuesto, a todos los voluntarios que asistieron al mismo. 
ciones de rocas blandas, margas y margocalizas o areniscas, pobladas de olivares y secanos cerealistas (ONIEVA MARIEGES, 1977: 24), éstos últimos de manera residual. Dentro del relieve que ocupa Montefrío destacan algunas sierras que superan los 1000 m, la Sierra de Chanzas (1213 m) o la Sierra de Montefrío (1154 m).

El clima característico en la zona, es el típico mediterráneo (BOSQUE MAUREL Y FERRER, 2000: 29). Madoz hablaba de "una vegetación de robles y encinares” (MADOZ, 1987: 538,540), hoy muy residual y casi inexistente. Su efecto ha sido la progresiva deforestación quedando encinares degradados (chaparrales), coscojales y peonías (ONIEVA MARIEGES, 1977: 92).

La torre de las Cabrerizas se encuentra en una loma situada a unos 2.700 metros al $\mathrm{N}$ de la fortaleza de Montefrío, sobre el Barranco de Cabrerizas y próximo al Cortijo del Hoyón (coord. UTM: 410343N-4134465E), a 948 m de altitud (Fig. 1.). Los estudios anteriores nos dicen que "es una torre atalaya fronteriza de

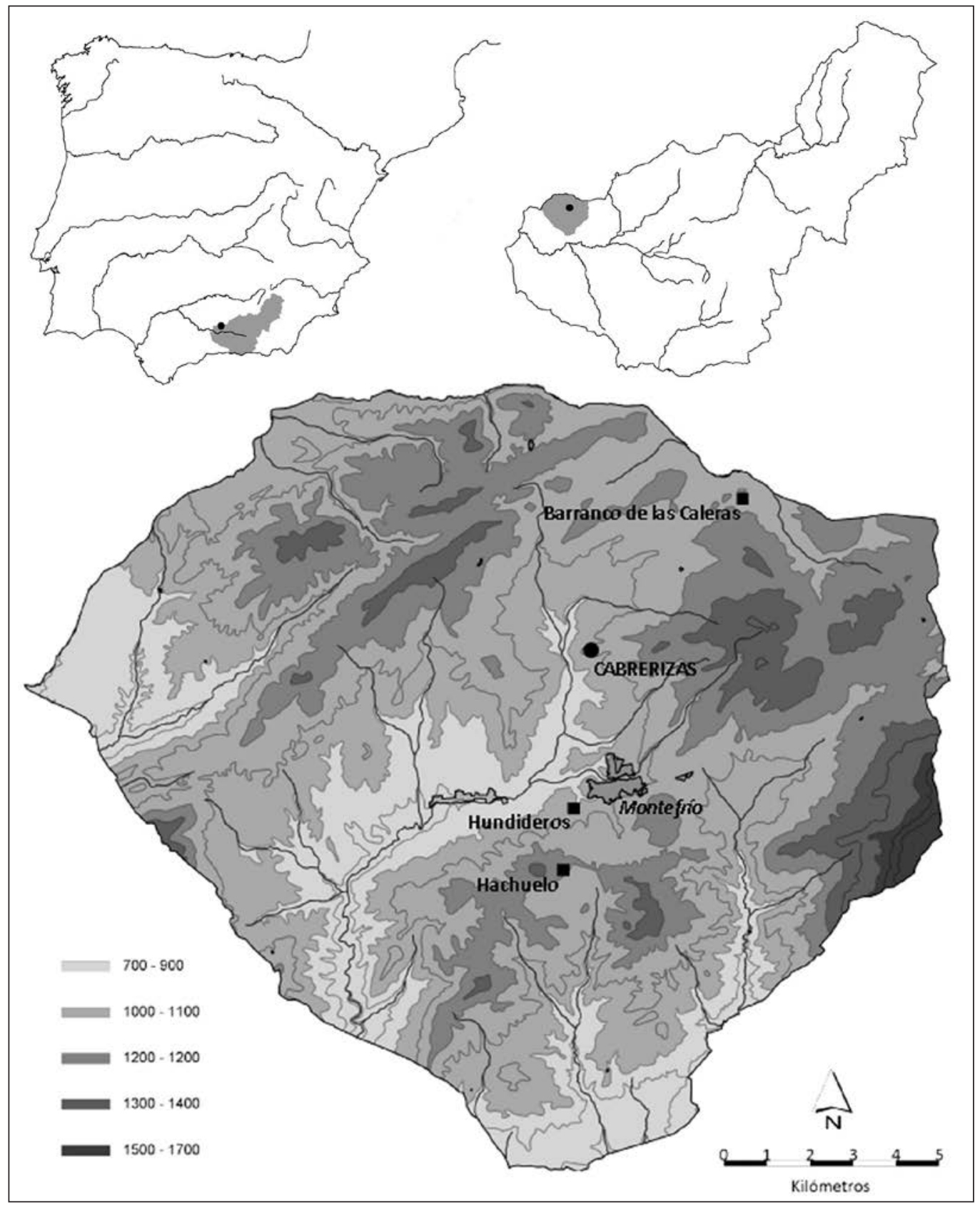

Fig. 1. Plano de ubicación de la Torre de las Cabrerizas 
época árabe, con figura cilíndrica y planta circular. Estaba construida con mampostería, no quedando de ella más que un montón de piedras, con hueco central, de 1 m de altura" (MARTÍN GARCÍA et alii, 1999: 332-333; MARTÍN Y MARTÍN, 1998: 505).

En el entorno de la torre de las Cabrerizas se localizan el arroyo del Chorro que desemboca en el Milanos, y en sus inmediaciones la actual Fuente de Sandoval, recursos que abastecerían a la población encargada de su control.

La atalaya de las Cabrerizas controlaba el territorio de la zona norte de Montefrío, sector fronterizo con Alcalá la Real, a través del paso de las Angosturas, apoyada por la torre del Romeral, al otro lado. De ésta, no se conservan restos, pero si noticias de su ubicación, por información oral, así como por la información recogida en el Libro de Apeo, que la denomina "Torre del Rosal Bajo" (JIMÉNEZ COMINO, 2009).

Dicha atalaya fortalecería el control de los pasos naturales de penetración cristiana al SO de la torre del Espinar, completando parte del sistema defensivo al $\mathrm{N}$ de la fortaleza o villa de Montefrío, sobre todo a mediados del siglo XV cuando tendrán lugar numerosas incursiones por parte de las tropas castellanas provenientes de Alcalá la Real.

\section{CONTEXTO HISTÓRICO}

Montefrío era conocido en época romana con el topónimo Mons Frigidus (Montefrío), en época medieval pasaría a denominarse Hișn Montefrid (LINARES PALMA, 1964: 17; CARRASCO RUS et alii, 1986: 186). Aunque por el momento, no conocemos el lugar que ocupó el asentamiento en época romana, siendo la construcción del castillo nazarí una reorganización de la frontera, tras la caída de Alcalá la Real (1341) Ya en el siglo XIV, Ibn al-Jațīb lo cita entre los límites actuales de las Barāyilat, éstas se reducían exclusivamente a "distritos que en los primeros años de la conquista fueron asignados a determinadas tribus árabes". El topónimo Muntifrīd (=Montefrío) sería un castillo-fortaleza "de las Barāŷilat de Garnata" (JIMÉNEZ MATA, 1990: 156-157; ALAWNA, 2003: 398). LaS Barāyilat serían zonas abruptas caracterizadas por ubicarse en tierras de paso o puerto. También la zona de Montefrío se conocía con el topónimo Muntifid o tal vez Muntfarid (Monte Único), castillo o hiṣn englobado en las sierras subbéticas (PEINADO SANTAELLA, 1997: 9; SECO PAREDES, 1974: 62).

Montefrío surge tras la consolidación del Reino Nazarí, en una etapa caracterizada por el avance y retroceso de la línea de frontera en la zona de Córdoba y Jaén, que iría de 1264 a 1369. Se trata de una época protagonizada por las luchas y campañas de Alfonso XI (1311-1350), que tras la batalla del Salado o del Estrecho (1340) conquistará Alcalá la Real, Castillo de Locubín, Priego, Rute y Benamejí, entre otras, en 1341 (JIMÉNEZ PUERTAS, 2002: 147). En este momento se reorganiza la frontera noroccidental del Reino de Granada, siendo Montefrío uno de los castillos fronterizos más avanzados con relación a los castellanos.

En tiempos de Yūsuf I, Ibn al-Jațīb menciona un alfaquí que nació y murió en Montefrío, un tal Abū'Alī al-Gafrūn al-Kalbī (m. dū-l-hị̂ŷa del $744 \mathrm{H}=$ del 15-4-1344 al 14-5-1344) (SARR Y MATTEI, 2011: 410). A la reorganización de la frontera y de sus defensas dedicó un especial empeño el sultán Muhammad V (13541359/1362-1391). Ibn al-Jațīb recoge en la Ihāța (IBN AL-JAṬīB, 1978: 51,78, BORDES GARCÍA, 2001: 71) dicha organización fronteriza, que estuvo acompañada por la construcción de diversas torres-atalayas, aunque algunas ya existirían, reutilizándolas en esta época; otras, en cambio, serían construidas ex novo para el control de los pasos entre el interior y la capital, a través de la vega. Dentro de este sistema existían torres de alquería que se encargaban de proteger a las comunidades campesinas del poblamiento rural que habitaban "las villas", en caso de cabalgadas cristianas. En Montefrío, contamos con la mención en la Crónica del Condestable Don Miguel Lucas de Iranzo de la Torre de Nunes (SORIANO, 1993: 198-199). Se creaba, de esta manera, una línea fronteriza en el sector noroccidental del Reino de Granada, con las fortalezas de Montefrío, 
íllora y Moclín, que apoyadas por una serie de torres-atalayas (Cabrerizas, Anillos, Espinar, Sol, etc.) controlarían los pasos de los valles mediante señales visuales.

Desde finales del siglo XIV hasta principios del XV, la frontera se mantuvo sin cambios. Tan sólo hay que destacar dos hechos en este sentido: la toma de Antequera (1410) y la posterior caída de Archidona (1462). Durante este período, se tomarán una serie de territorios muy cercanos a Montefrío, pertenecientes administrativamente a la ciudad de Loja, como fueron Cesna (1435) y Pesquera (1436) (JIMÉNEZ PUERTAS, 2002: 242), castillos y torres que constituirán, desde entonces, una amenaza para el territorio de Montefrío. Además se producirían distintas luchas entre abencerrajes y legitimistas dentro del propio estado nazarí, como el pronunciamiento de Montefrío a favor de Ibn al-Mawl (futuro Yūsuf IV) en 1431 (SALVATIERRA CUENCA et alii, 1989: 231) por el control de la capital Granada.

Podríamos pensar que la construcción de la torre de las Cabrerizas, pudo ser realizada a mediados del siglo XV, cuándo se generalizan las campañas y cabalgadas en la zona de Montefrío, con el monarca Enrique IV (1425-1474) entre los años 1455-1463, y las cabalgadas del Condestable Don Miguel Lucas de Iranzo en 1463-1464, mencionando las crónicas diversas hazañas y enfrentamientos en la zona. Ya que otras torres, como la del Espinar al E, y la del Romeral o Loma de Marcos situadas al O y NO de las Cabrerizas vigilarían los pasos de las posibles incursiones castellanas anteriores a estos momentos, que serían mínimas y no tan frecuentes por los grandes períodos de paz de finales del siglo XIV.

\section{La investigación en las Torres-atalayas de Montefrío}

Las torres de Montefrío han sido objeto de diversos trabajos de índole científica en los que se han abordado distintos aspectos referentes: a intervenciones arqueológicas, técnicas constructivas, estado de conservación, cronología y funcionalidad en la frontera occidental del Reino de Granada (BELLÓN Y
PEDREGOSA, 2004, ÍDEM, 2010; PEDREGOSA MEGÍAS, 2007a y 2007b; ARGÜELLES MÁRQUEZ, 1995; MALPICA CUELLO, 1996; MARTÍN GARCÍA et alii, 1999; MARTÍN y MARTíN, 1998; SALVATIERRA et alii, 1989).

El sistema defensivo de Montefrío estaría compuesto por unas 15 torres -al menos-: las del Sol, Hachuelo, Loma de Marcos, Romeral (Torre del Rosal), Cabrerizas, Espinar, Quebrada, Matute, Anillos, Loma de la Torrecilla, Guzmanes, Cortijuelo, Torre Nunes, Castillejos y Cerro de la Torre (límite con Villanueva de Mesía). Los datos que tenemos sobre ellas proceden de diversas fuentes; la arqueología, las fuentes históricas o crónicas, el Libro de Apeo, la toponimia conservada y la información oral. Estarían situadas en zonas altas o abruptas, en cerros elevados que permitían la comunicación directa frente a las correrías cristianas. Tienen, por tanto, una clara función de vigilancia y control del territorio, avisando a la población rural indefensa de las venidas cristianas desde el otro lado de la frontera (PEDREGOSA MEGÍAs 2010a).

Actualmente se conservan restos de 9 torres o estructuras: las del Sol, Hachuelo, Cabrerizas, Espinar, Quebrada, Anillos, Guzmanes, Cortijuelo y Cortijo de los Castillejos (de ésta última no está clara su cronología y tipología). De la mayoría conocemos su ubicación geográfica, si bien, del resto no quedan elementos constructivos evidentes, pudiendo existir restos de su cimentación, hecho que habría que comprobar arqueológicamente (PEDREGOSA MEGíAs, 2011a: 64).

Parece ser que existiría un programa constructivo dentro del Reino Nazarí en la construcción o levantamiento de diversas atalayas, siguiendo unos parámetros similares, tanto en técnicas constructivas, ubicación y materiales a utilizar, independientemente de la zona en la que se construyesen. Al tratarse de una obra promovida por el poder, tiene unas constantes formales claramente identificables (ALMANSA, 1999: 437; DE LUQUE, 2003: 37,82; MALPICA CUELLO 1998a: 273, 2003: 139). Nos encontramos con una mampostería regular, cuyos mampuestos eran distribuidos en hiladas horizontales, que se enmarcan entre verdugadas de ripios y lajas. 
Las torres se construían en cerros elevados con un buen control visual, hecho que repercutía en su construcción, condicionando tanto el abastecimiento de materiales (piedra, morteros, agua, vigas para el andamiaje) como el transporte de los mismos, la llegada de los alarifes y los encargados en la construcción de las mismas. Toda esta logística influiría en la construcción y mantenimiento de las distintas estructuras militares.

\section{LA INTERVENCIÓN ARQUEOLÓGICA}

La estratigrafía ${ }^{2}$ documentada en la intervención arqueológica fue muy sencilla y contamos con unas pocas unidades. Un nivel superficial de la cubierta vegetal (UE100), en la que documentamos distintos fragmentos de cerámica nazarí.

Un nivel de derrumbe de parte de la estructura constructiva (UE101) que cubría el cuerpo macizo de la torre (UEC102), construido mediante la técnica de mampostería enripiada. Las medidas conservadas de la torre rondan una altura de $97 \mathrm{~cm}$ en la zona NO, y $21 \mathrm{~cm}$ en la zona SE, y un diámetro de $5 \mathrm{~m}$. En el cuerpo de la torre aparecieron restos de enlucidos aunque muy alterados en la zona E, además de la capa previa de argamasa o cal sobre la cual iría el enlucido.

Asociado al cuerpo de la torre destaca un mortero de cal disgregado, piedra y tierra UEC103), de menor altura, debido a la búsqueda del famoso tesoro realizada en momentos recientes. La diferencia de cota se da en una superficie de $1,97 \mathrm{~m}$ de longitud y $1,86 \mathrm{~m}$ de anchura (Fig. 2 y Lám. Ila).
A lo largo de la estructura se conservaba una capa de mortero o revoco (UEC104) que cubriría el cuerpo cilíndrico de la estructura, muy alterado y disgregado por la bioturbación, provocando desplacación, fisuras, grietas, además de otras alteraciones. Este revoco estaba cubierto por un enlucido de cal de un color grisáceo que cubría toda la estructura (UEC105), (Lám. I a y b).

Se realizó un sondeo estratigráfico de $2 \times 2$ m., para comprobar la técnica constructiva y cimentación de la torre en su lado SE, cercano a la zona de rebaje y destrucción antrópica del cuerpo macizo de la misma, ocasionada por la progresiva extensión de la franja de cultivos de secano. Se trataba de una zona



Fig. 2. Planta y sondeo arqueológico Torre de las Cabrerizas

2 Hemos diferenciado entre UE y UEC (Unidades estratigráficas no construidas y construidas) y UEM para el análisis de las unidades observadas en el alzado desarrollado de la estructura que forma la torre de las Cabrerizas). 

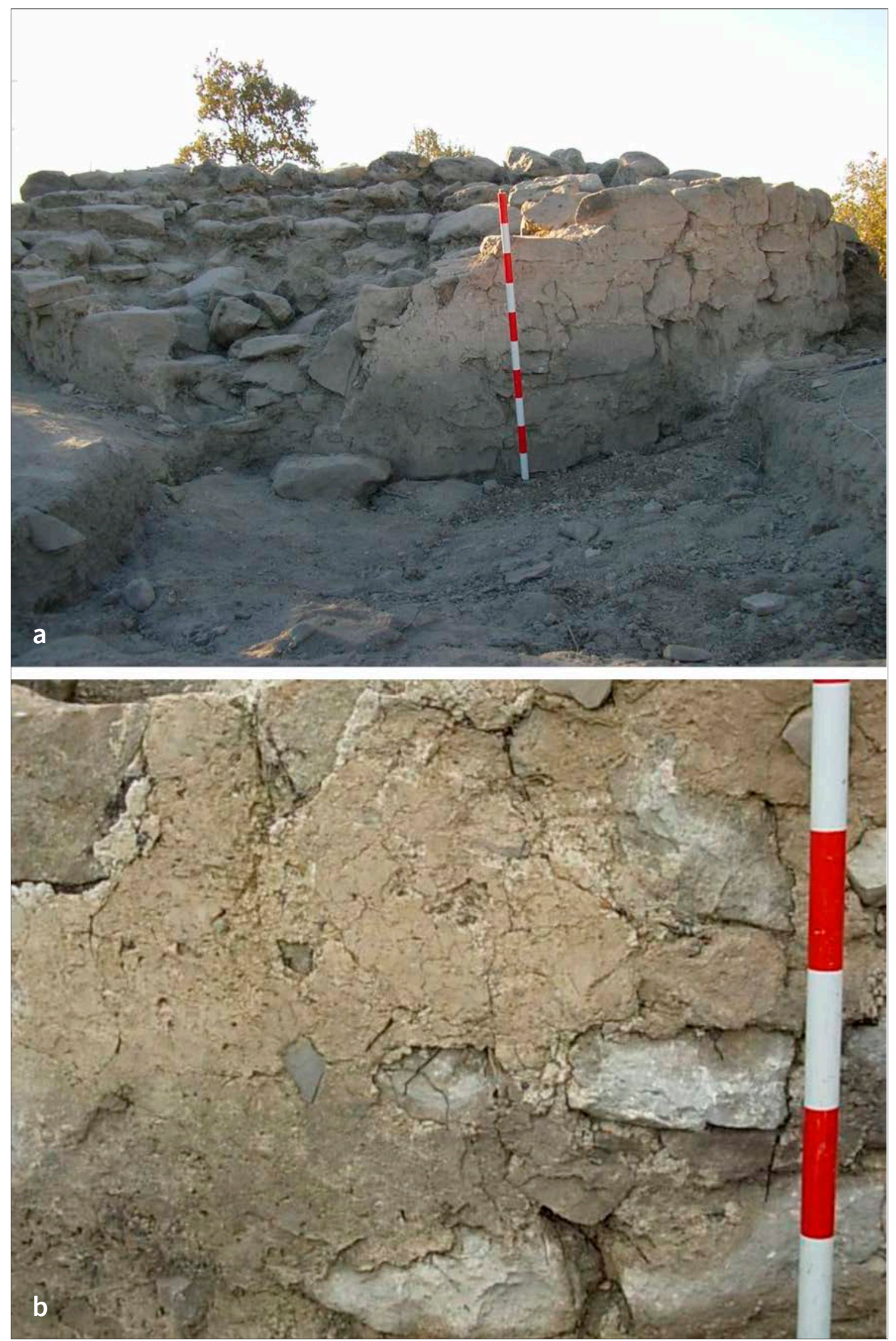

Lám. I. Alzado SE de la torre de las Cabrerizas (a). Detalle del enlucido y lágrima (b). 
caracterizada por la relativa frecuencia de materiales cerámicos, durante la retirada de la cubierta vegetal. También aparecía un depósito de color beige-blanco blando y de textura arcillosa, con algunas manchas oscuras grises producidas aparentemente por algún fuego $u$ hoguera realizada en la zona. De esta manera, decidimos realizar el sondeo en dicha zona para descartar que esas manchas de ceniza y tierra quemada pudieran estar relacionadas con actividades contemporáneas asociadas a los cultivos colindantes

El principal resultado fue la localización de un depósito de cenizas correspondiente al lugar donde se ubicaría la cocina u hogar, caracterizado por aprovechar la diferencia de cota entre los afloramientos de calizas para cocinar directamente sobre ellas, colocando las ascuas entre los huecos de dichos afloramientos rocosos, y sobre éstos, colocar a modo de es trébedes el artefacto cerámico. Este es uno de los lugares donde prepararían los alimentos los encargados de la vigilancia del sector ocupado por la torre de las Cabrerizas.

\section{La cerámica}

En la torre de las Cabrerizas están representadas algunas de las formas clásicas de la vajilla nazarí, documentadas tanto en el entorno como en el sondeo realizado. Figuran entre ellas cazuelas, marmitas, jarritas/os, jarra/o, lebrillos o alcadafes, tinaja y tapadera, no apareciendo material correspondiente a la vajilla de mesa como ataifores, jofainas o cuencos. La cerámica que documentamos es muy homogénea de mediados del siglo XV, siendo las producciones documentadas las destinadas al servicio de cocina, usos múltiples y servicio de mesa para la contención de líquidos, todas ellas dentro de la cerámica común, usadas por el grupo de soldados o guarnición al cargo del control y mantenimiento de la torre.

\section{TÉCNICAS CONSTRUCTIVAS Y ARQUITECTURA ${ }^{3}$}

Tras los trabajos realizados, pudimos comprobar el diámetro y la altura de la torre-atalaya de tendencia cilíndrica, con un perímetro de 14,60 m y un radio de $5 \mathrm{~m}$ (Figs. 2, 3), con una altura superior a $1 \mathrm{~m}$, conservada en 6 hiladas horizontales de mampostería concertada o enripiada UEM200. La construcción se realizó sobre los afloramientos de caliza que surgen en el entorno de la torre. Sobre éstos, se niveló el terreno con pequeñas piedras y lajas sobre las que se colocó la primera hilada de mampuestos.

La técnica constructiva utilizada es la mampostería enripiada, que se caracteriza por el empleo de ripios o pequeñas lajas, colocadas de manera horizontal (MALPICA CUELLO, 1998B: 301). Los mampuestos fundamentalmente calizas, areniscas y margas serían de diverso tamaño y se colocarían a mano. En algunas ocasiones pueden trabajarse los ripios para darle cara y adaptar su tamaño o forma, organizando su colocación posterior, para que encajen unos mampuestos con otros, o bien

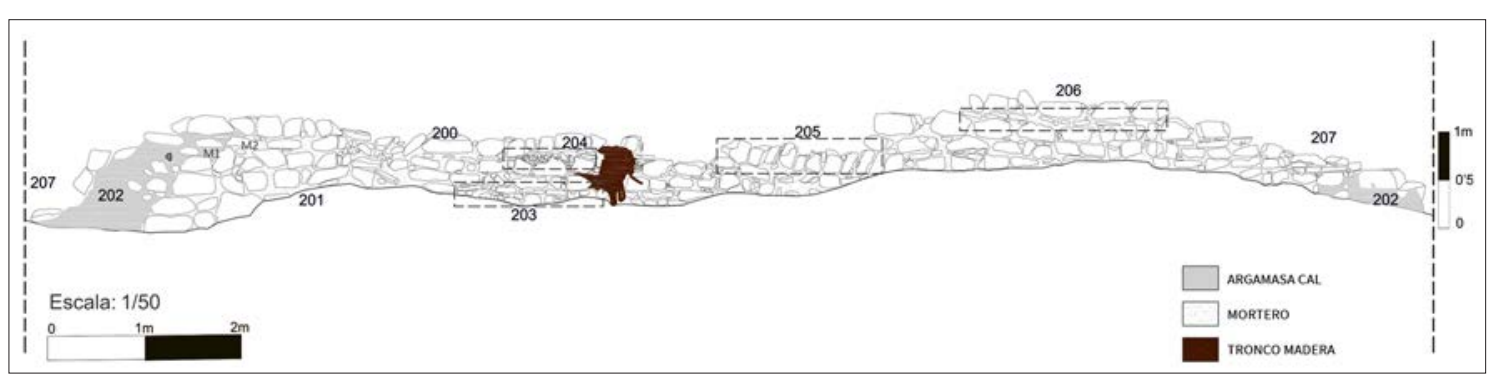

Fig. 3. Alzado general de la Torre de las Cabrerizas, Montefrío (Granada).

3 Agradecemos la colaboración prestada por parte del profesor de Historia Medieval de la Universidad de Granada José María Martín Civantos, en sus correcciones e indicaciones. 
añadirle ripios de pequeño tamaño. La unión de los mampuestos se hace mediante mortero de cal más o menos rico, con tierra o dispuestos a hueso o piedra seca. En su acabado exterior puede dejarse vista o rejuntarse con mortero de cal que le dará mayor consistencia; un rejuntado que puede ser más grueso hasta llegar a ser casi un enfoscado total del muro que solo deje ver parte de los mampuestos a través de un llagueado en vitolas (MARTín CIVANTOS, 2001 2002: 186).

El número de hiladas conservadas es de 6 , con una altura $1,20 \mathrm{~m}$, quedando una sola hilada en el sector S de la propia estructura, donde un hueco rebaja el relleno interior de la propia construcción (Fig. 2). Este desnivel se debe a causas antrópicas de finales del siglo XX. El número de hiladas varía en función de la altura conservada en las demás torres, 19 en la torre de los Anillos con una altura de 3,50 $\mathrm{m}$, en la torre de los Guzmanes 31 hiladas con una altura de 4,80 m, 10 hiladas en la torre del Sol con una altura de casi 2 m, 13 hiladas en la del Espinar siendo su altura de más de $2 \mathrm{~m}$ aunque ésta sería mayor. En el Cortijuelo 31 hiladas con una altura de $5.75 \mathrm{~m}$. El número de hiladas está relacionado con el tamaño de los ripios y la llaga de mortero empleada en su unión variando según el caso. El tamaño de los ripios empleados en la construcción oscila entre $35-50 \mathrm{~cm}$ de longitud, con una altura entre $10-20 \mathrm{~cm}$, frente a los más pequeños 6-15 cm de longitud y los 4-10 cm de altura. En la torre de los Guzmanes las dimensiones de los mampuestos serían similares $15-40 \mathrm{~cm}$ de altura y $35-60 \mathrm{~cm}$ de longitud, presentando los ripios menores una altura entre $12-15 \mathrm{~cm}$ y una longitud que oscila entre $10-20 \mathrm{~cm}$.

En el Espinar los ripios mayores oscilan entre una longitud de $35 \mathrm{~cm}$ y una altura de 20-30 cm, frente a los menores con una longitud de $15-20 \mathrm{~cm}$ y una altura de unos 6-7 cm. La torre del Sol presenta unos mampuestos con dimensiones de $10 \mathrm{~cm}$ de altura por $38 \mathrm{de}$ longitud, los menores oscilan entre los $2-5 \mathrm{~cm}$ de altura y $l o s$ 6-10 cm de longitud. En cambio en la torre del Cortijuelo los mampuestos son de mayor tamaño 40-90 cm de longitud y una altura de unos $20 \mathrm{~cm}$.
Los ripios de menor tamaño se introducirían en las juntas entre los mampuestos de mayor tamaño, así como en aquellas partes de la estructura utilizadas en la nivelación de la propia construcción. Lo normal es que se dispongan hiladas regulares ripiando en los puntos en que es necesario para que la horizontalidad de las hiladas no se altere (ESLAVA GALÁN, 1984:276). De esta manera se corrige el desnivel en la hilada y se construye sobre una superficie bastante horizontal (MARTíNEZ LILLO, 1990:169). Ejemplo que hemos documentado en el análisis de las distintas atalayas que se encuentran en Montefrío, ya que utilizan en su construcción una mampostería enripiada, salvo en la torre de los Anillos que aprovecha una serie de sillares de caliza de gran tamaño que forman parte del alzado $S$ y alternan a lo largo del desarrollo de la estructura con distintas reparaciones en mampostería, claramente con una cronología anterior cuánto menos de época iberomana aprovechada posteriormente en época Califal (PEDREGOSA Y MARTíNEZ, 2014:549).

Una vez realizada la obra en mampostería se realizarían los enlucidos que recubrirían la estructura, en ocasiones existe una fina capa exterior que protegía la propia construcción, impermeabilizándola y aislándola, a la vez que contribuía a embellecerla. Generalmente se trata de un mortero de cal y arena al que en ocasiones podía añadirse yeso y otras arcillas. El enlucido se aplicaba una vez seca la obra, sobre la cual suelen labrarse una serie de acanaladuras para facilitar de este modo la adherencia del mismo (ESLAVA GALÁN, 1984: 274).

La Torre de las Cabrerizas conserva restos de enlucido UEM202 (Lám. I y Fig. 3) que recubría la torre en su lado SE y se prolongaría en dirección SO, hasta llegar a la parte más baja. Los restos conservados tienen una extensión de $1 \mathrm{~m}$ de altura y casi $2 \mathrm{~m}$ de longitud. Algunos ripios quedarían vistos a modo de vitola, aunque éste hecho, no podemos confirmar que sea intencionado. El otro resto de enlucido se localiza en dirección SO, quedando a la izquierda del butrón, con una longitud de $1.10 \mathrm{~m}$ y una altura de $0.25 \mathrm{~m}$. 

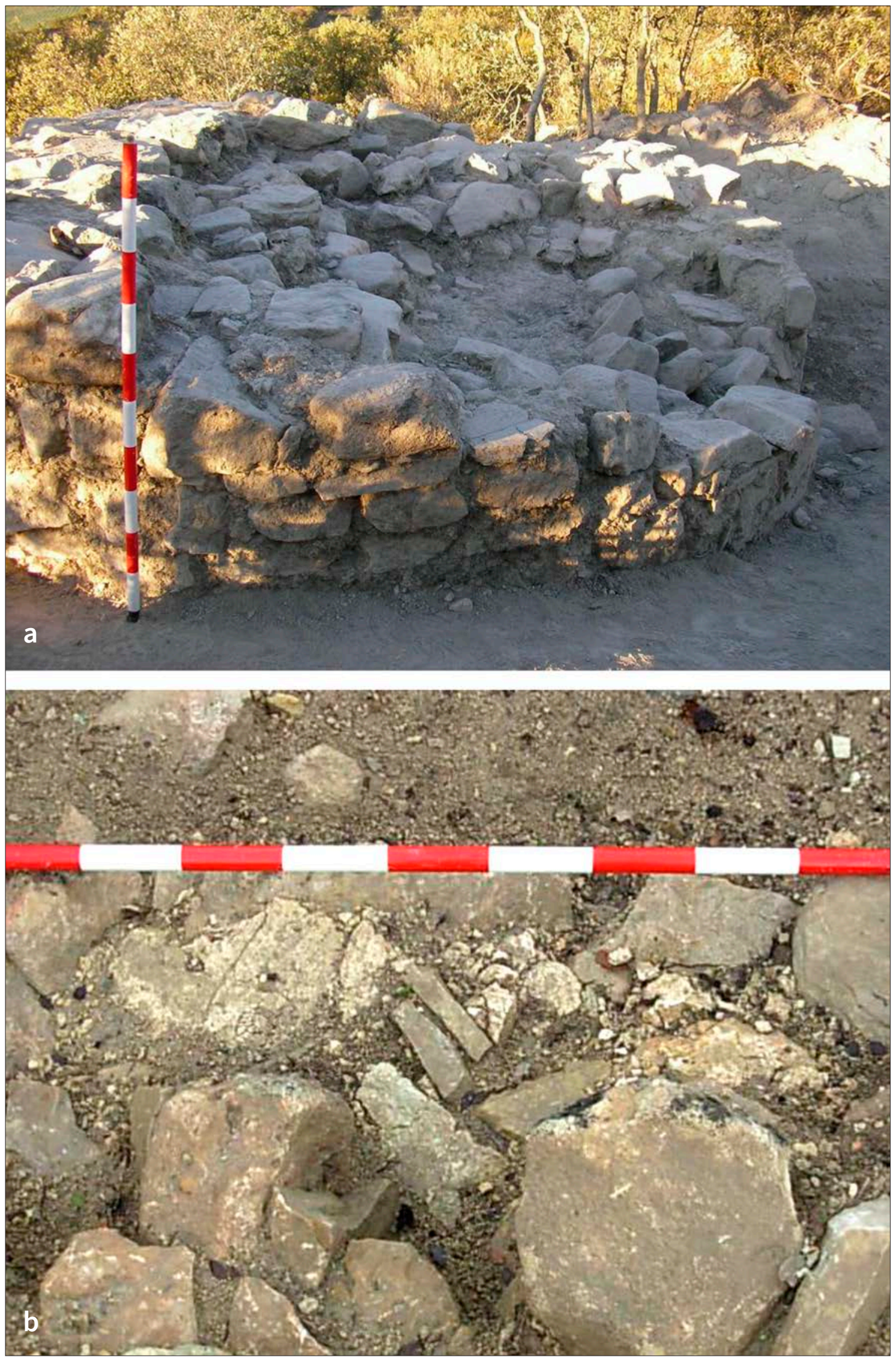

Lám. II. Butrón en la zona S UEC103 (a). Detalle de lechada de cal (b). 
También observamos la capa previa de argamasa o mortero de cal UEM201, sobre la que iría el enlucido, con un grosor que oscila entre los 0.5 y los $1.5 \mathrm{~cm}$, muy similares a los hallados en la cercana torre del Espinar. En ésta, se documentó un enlucido en el lado NE de la misma, fabricado con mortero de cal de color grisáceo. Las dimensiones conservadas van de $2.90 \mathrm{~m}$ de longitud a una altura de $0.91 \mathrm{~m}$ y un grosor que oscila entre los 0.5 y el $1.5 \mathrm{~cm}$ conservados (PEDREGOSA MEGÍAS, 2007b:218; ÍDEM, 2010b:1297). En la torre del Sol pudimos comprobar que cubriendo la estructura muraría existía un enfoscado o revoco, compuesto por mortero de cal, con un grosor que oscila de los 0.5 a los $0.8 \mathrm{~cm}$, previo al enlucido (PEDREGOSA MEGÍAS, 2007b: 218; ÍDEM, 2010b: 1296). En la torre e Agicampe (Loja) se observa un mortero rico en cal muy perdido, al igual que el posible enfoscado que cubriera los paramentos (GARCÍA PULIDO, 2013) ${ }^{4}$.

Otros restos de enlucido se conservan en la Torre del Sol con un área conservada de 1.50 por $0.26 \mathrm{~m}$. Y en las torre de los Anillos y Cortijuelo restos a modo de vitola que recubre parcialmente los mampuestos. Incluso observamos gran cantidad de mortero en la Torre del Cortijuelo utilizado en diversas reparaciones, similares a las observadas en la muralla del recinto de la villa de la fortaleza de Montefrío. Dichas reparaciones unidas al sistema de encofrados permiten dar una cronología más tardía para la construcción de dicha torre en la segunda mitad del siglo XV.

La argamasa utilizada en este tipo de construcciones está formada por cal, yeso, tierra, piedra y grava (MALPICA CUELLO, 2003: 304). Como veremos a continuación en el análisis de las muestras, los morteros de revestimiento serían ricos en áridos, elaborados mezclando de dos a tres partes de gravas y arenas por cada parte de la pasta aglomerante hecha a base de cal, barro (limos y arcillas) y arenas muy finas (2.3:1 - 3:1). Mientras que en los enlucidos, destaca la presencia mayor de cal y sílice, principalmente compuesto por arenas muy finas.

Incrustado en el propio enlucido, se puede apreciar, lo que podría ser un elemento de decoración, el detalle de una lágrima, de forma romboidal y realizada en sílex (Fig. 3 y Lám. I b). Es común que en algunas ocasiones, sobre las piedras que recubren la vitola se encuentren incrustados algunos guijarros o escorias (MALPICA CUELLO, 1998b: 301; MARTín CIVANTOS, 2001-2002: 186) como observamos en las Cabrerizas, además de en otras torres y castillos nazaríes de la provincia de Granada, como en Torre Pesquera (Algarinejo).

En dirección occidental a la raíz se aprecia la UEM203, en la propia línea de cimentación con una longitud de más de 1.60 m y una altura de unos $20 \mathrm{~cm}$, compuesta por piedras y lajas de pequeño tamaño, de diferente forma unas más planas y otras más gruesas, que sirven de relleno y nivelación de parte de los afloramientos rocosos sobre la que se asienta la construcción. Por encima, en éste mismo sector, podemos observar la UEM204, que consiste en una solución para nivelar la hilada, ripiando la superficie con $80 \mathrm{~cm}$ de longitud y $15 \mathrm{~cm}$ de altura. Ésta unidad está compuesta por pequeñas piedras y mortero de cal que rellenan esa zona. En este mismo sector, aunque en su base, se puede comprobar el relleno con piedra de pequeño tamaño y mortero para la nivelación del terreno.

Siguiendo con el análisis constructivo la UEM205, consiste en una hilada de mampuestos colocados de forma vertical o en forma de espina, con una longitud cercana al $1.80 \mathrm{~m}$ y una altura aproximada de $0.30 \mathrm{~m}$, cuya función es la regularización en la horizontalidad de las hiladas más bajas. Otra regularización en la estructura es la que hemos denominado UEM206, donde podemos ver como se nivela

\footnotetext{
4 Esperemos que el proyecto que se está llevando a cabo en la torre de Agicampe, plantee un análisis de los morteros de fábrica utilizados en la misma, lo que permitiría una comparación entre los materiales utilizados en la torre de las Cabrerizas.
} 
la última hilada de mampuestos conservada, compuesta por pequeños ripios o lajas, con casi una extensión de $2 \mathrm{~m}$ de longitud.

Por último la UEM207, que apreciamos en ambos extremos del alzado general de la torre, se corresponde con el rebaje o butrón (Lám. II, a), siendo la altura conservada menor en planta.

La torre presenta alteración provocada por bioalteración, fundamentalmente raíces y el troncón de un chaparro, como consecuencia de los procesos geomorfológicos externos. El estado de conservación del enlucido y de la capa de enfoscado presenta grietas, fisuras y desplacados, por la acción de la bioturbación (PEDREGOSA MEGÍAs, 2007a: 291-292).

\section{La relación constructiva entre la torre de las Cabrerizas y el resto de las localizadas en Montefrío}

El sistema constructivo empleado en la parte maciza partiría del paramento exterior del cilindro, rellenando posteriormente las hiladas interiores a través de líneas concéntricas desde el exterior hacía el interior de la estructura. La construcción del núcleo macizo y del relleno interior de la base presenta un cuidado extremo que se observa en la configuración de líneas concéntricas unas a otras, trabadas con una buena capa o lechada de mortero de cal como observamos en la atalaya de las Cabrerizas (Lám. II b) y en las demás. El diámetro que presentan las diversas atalayas ronda los 10 codos ma'muni, salvo en la torre del Cortijuelo y de los Anillos que es mayor al adaptarse al terreno y a la reutilización de la estructura previa en el caso de los Anillos.

Las estructuras militares se han construido sobre los afloramientos de caliza, que surgen en el entorno de las torres que caracterizan la geología de Montefrío. Sobre estas crestas calcáreas se ha nivelado el terreno con pequeñas piedras y lajas sobre las que colocar la primera hilada de mampostería, sobre una capa o lechada de cal bastante gruesa y rica en cal, dando solidez a la cimentación de la estructura hecho que observamos en las torres del Cortijuelo, Cabrerizas, Espinar Anillos y en los elementos defensivos tanto de las murallas como torres del castillo de Montefrío. Utilizan fundamentalmente calizas, margas y areniscas, que afloran en las cercanías donde se ubican los elementos. Algunas de las torres presentan sus paramentos ataludados Cortijuelo, Anillos, Guzmanes e incluso las torres no 1 y n07 en el recinto de la villa del castillo de Montefrío (PEDREGOSA MEGÍAS, 2010a).

En todas, la técnica constructiva empleada es la mampostería enripiada, de ripios colocados en hiladas horizontales paralelas unas a otras, con pequeñas piedras o incluso fragmentos de tejas o cerámica en las uniones de los mampuestos, como podemos observar en la torre del Espinar (PEDREGOSA MEGÍAS, 2007b: 217), y en las torres del Sol, Espinar y Cabrerizas, incluso en la torre no 7 de la muralla del recinto villa en el castillo de Montefrío, hecho muy común en este tipo de construcciones (MALPICA CUELLO, 2003: 301). En la fabricación de los distintos elementos defensivos tan sólo la torre de los Anillos presenta una reutilización de grandes bloques o sillares de caliza de una construcción anterior (PEDREGOSA MEGÍAS, 2011b:197).

Los materiales constructivos (arenas, gravas y piedras) procedían de las inmediaciones. La cal probablemente la obtuviesen de una zona conocida como "Las Caleras" y otras referencias toponímicas, así como otras canteras localizadas (Fig. 1), siendo el agua utilizada para los morteros la procedente de los diversos arroyos, cañadas e incluso fuentes cercanas a la propia ubicación de las torres.

La estructura de las torres contaría con un primer cuerpo macizo de mampostería enripiada, que podría tener unos $5 \mathrm{~m}$ de altura como observamos en la torre del Cortijuelo la mejor conservada. El cuerpo de dichas estructuras podría tener adosado a sus paramentos alguna construcción como podemos intuir a través de los huecos observados en la torre de los Guzmanes, frecuente en otras, como en la Torre de Maruq (Freila), donde el torrero quizás pudo vivir en esa construcción aneja a la propia torre (RUBIO Y MORENO, 2006: 55). 
El cuerpo macizo se levantaría en cajones - cuerpos de fábrica con una altura de cajón de 0.85-0.90 m lo que equivale a dos codos ma'muni siendo la separación de las agujas entre 0.90 y 1.40 longitud, como observamos en la torre del Espinar y Cortijuelo. Los mechinales documentados en las atalayas de Montefrío presentan unas dimensiones de 10 $\times 12 \mathrm{~cm}$ en el caso del Cortijuelo frente a los del Espinar que presentan unas medidas de $11 \times 13 \mathrm{~cm}$. Las agujas atravesaban todo el cuerpo de la estructura maciza y eran recortadas al finalizar la obra, posteriormente se enfoscaban y enlucían.

En las atalayas de Montefrío hemos podido documentar un máximo de 6 cajones o cuerpos de fábrica en la Torre del Cortijuelo, entre 2 y 3 en la torre del Espinar y 4 en la Torre de los Guzmanes, teniendo la torre del Sol en torno a 2 cajones y la de las Cabrerizas 1 , frente a los 4 cajones de la torre de los Anillos.

En la estructura maciza suele ubicarse un depósito de agua o aljibe como podría ocurrir en la torre del Espinar donde documentamos un fragmento de atanor, para la recogida o conducción de las aguas de lluvia a través de la terraza, que desembocaría en un deposito - aljibe ubicado en la estancia habitable de la torre, como en el sector de Baza concretamente en la torre del Romeral (RUBIO Y MORENO, 2006: 55).

A partir de la obra maciza, se construye la parte habitada, la mampostería se hace vista tanto al exterior como al interior, dejando los huecos necesarios para el acceso, troneras, chimeneas y escaleras.

Debido al estado de conservación de las atalayas ubicadas en Montefrío no contamos con ninguna completa, aunque si tenemos elementos para saber y conocer su estructura y distribución interna. Durante los distintos trabajos realizados pudimos documentar el dintel del vano de acceso de la torre del Espinar (PEDREGOSA MEGÍAS, 2007:219), además de dos elementos constructivos que formarían parte del habitáculo en la torre del Sol, una jamba de unos $80 \mathrm{~cm}$ de longitud, y una quicialera o gorronera realizada en arenisca donde iría la viga de madera que cerraría la estancia superior de la torre, con una longitud de más de $25 \mathrm{~cm}$ y un orificio de $12 \mathrm{~cm}$ de diámetro. Por los datos de que disponemos y la zona donde aparecieron los elementos constructivos pensamos que los vanos estarían orientados al SE, en el caso de la torre del Sol, Espinar frente al Cortijuelo que tendría su entrada orientada al NE según las evidencias observadas.

La habitación podría estar empedrada como en el caso de la torre del Cortijuelo. Y estaría cubierta por una bóveda semiesférica rebajada, cuya imposta se situaría a $2 \mathrm{~m}$ de altura. Las escaleras de subida a la terraza se construían de la misma mampostería de altas tabicas, para disminuir su desarrollo. Por último, se levantaba el peto de la azotea y la garita que cubría la subida de la escalera y el cañón de la chimenea (MARTín GARCíA et alii, 1999: 35-36).

\section{APROXIMACIÓN AL ESTUDIO DE LOS MORTEROS DE REVESTIMIENTO Y ENLUCIDOS}

A continuación pasamos a analizar el estudio de algunas muestras del mortero de revestimiento y enlucido procedentes de los paramentos exteriores de la Torre de las Cabrerizas. Los análisis se realizaron mediante técnicas de microscopía, a través de luz reflejada, lupa binoculary, principalmente, mediante microscopía electrónica de barrido (SEM) analizadas en el centro de Instrumentación Científica de la Universidad de Granada en Septiembre de 2006, junto a análisis de espectroscopia de rayos $X$ de energía dispersiva (EDX) realizadas por Juan Miguel Rivera quién suscribe este artículo en 2010.

En esta fase de investigación nos centramos con datos de carácter cualitativo en donde se incluyen también otros de tipo semicuantitativos. Los datos de tipo cuantitativo, van asociados principalmente al nivel de porosidad observada en la matriz de los distintos materiales que forman la muestra, se determinaron mediante técnicas de aná- 
lisis de imagen, desde los cuales se hacen interpretaciones acerca del comportamiento del mortero a través de los procesos de elaboración y puesta en obra.

El objetivo principal del estudio es obtener datos e información sobre la forma de elaboración o manufactura de estos materiales, con el fin de plantear hipótesis sobre las relaciones sociales que giraron en torno a la construcción de la Torre de las Cabrerizas y en las demás torres que se conservan en Montefrío.

Los datos obtenidos y los diferentes niveles de interpretación se ordenan en primer lugar atendiendo a la funcionalidad de los distintos materiales dentro de la fábrica de obra y, segundo, tomando en consideración los componentes principales de los morteros, tratando por separado áridos y matriz aglomerante. Dentro de éste último aspecto se identifica y describe la naturaleza de los distintos componentes para así plantear las posibles zonas de procedencia de las materias primas utilizadas y sus sistemas de obtención y/o producción. Por último, analizamos la configuración entre los componentes dentro de la matriz, centrándonos fundamentalmente en la microestructura, dosificación y la distribución entre los componentes minerales gruesos y finos, con el objetivo de establecer una aproximación a las formas de elaboración de las distintas mezclas e interpretar el carácter de las "fórmulas originales" y sus propiedades.

\section{Morteros de revestimiento}

Los morteros de revestimiento se definen como mezclas homogéneas compuestas por materiales aglomerantes (con capacidad ligante), agregados inertes o pasivos (áridos), como las arenas, aditivos (orgánicos o inorgánicos) y agua, que mezclados en proporciones adecuadas forman una pasta, que aplicada sobre los paramentos de cualquier tipo de fábrica dan trabazón a los distintos componentes que forman una obra de construcción. La función de los morteros es la de agarre o unión permitiendo enlazar y consolidar las unidades de construcción rellenando las grietas y espacios vacíos de los diversos tipos de fábricas, actuando además como barrera impermeable proporcionando una mejor resistencia frente a los agentes de alteración externos.

\section{ÁRIDOS O AGREGADOS INERTES}

Los áridos son los componentes minerales gruesos que proporcionan a la mezcla volumen, hacen de relleno y ayudan a disminuir la retracción del mortero durante el fragüe. No obstante, no contribuyen de manera activa al endurecimiento del mortero. La naturaleza de éstos y las posibles zonas de procedencia se interpretaron tomando en consideración sus composiciones químicas (EDX) comparándolas con las características geológicas del entorno del emplazamiento y atendiendo a sus rasgos morfológicos, tamaños y formas, documentadas a través de las distintas técnicas de microscopía (p. e. Lupa Binocular y SEM).

En el caso que nos atañe, a nivel de naturaleza, los componentes minerales hallados en los morteros de revestimiento muestreados se corresponden con las formaciones geológicas más próximas a la torre, estando representados por fragmentos de calcitas $\left(\mathrm{CaCO}_{3}\right)($ Lám. IIId.3), dolomías (CaMg ( $\left.\left.\mathrm{CO}_{3}\right)_{2}\right)$ (Lám. Illc.2) y cuarzos $\left(\mathrm{SiO}_{2}\right)$ (Lám. IIIc.1). Igualmente se han podido identificar la presencia de algunos fragmentos de rocas detríticas, como por ejemplo margas y calcarenitas.

A nivel de granulometría, los morteros de revestimiento utilizados en la construcción de la torre fueron fabricados a partir de mezclas ricas en áridos gruesos, en donde dominan las fracciones de tamaño "grava gruesa" (de 4-6.4 $\mathrm{mm}$ ), alcanzando una proporción un tanto mayor al $70 \%$, aunque también se encuentran muy pocos (<2\%) áridos de tamaño "arena gruesa" (entre 1-2 mm) (Lám. IIla).

Las formas que presentan los áridos a través de lupa binocular son tabulares, redondeadas y subredondeadas, lo que hacen pensar que las zonas de explotación de esta materia prima corresponden a aquellas relacionadas con los ambientes sedimentarios de tipo aluvial propio de las cuencas hidro- 

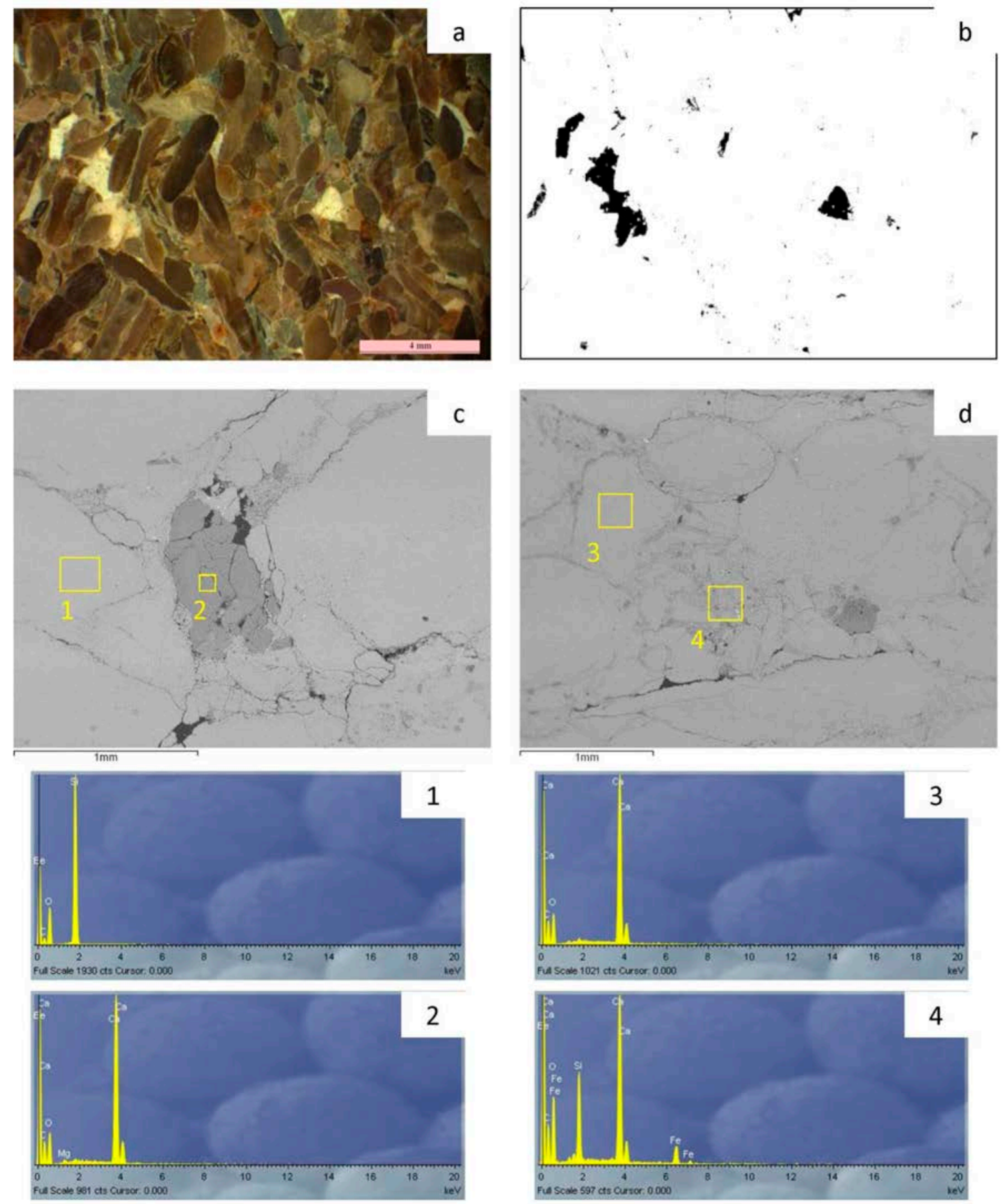

Lám. III. Muestras de mortero de revestimiento. a) Imagen tomada con lupa binocular; b) Resultado de análisis de imagen, porosidad; c-d) Imagen SEM; 1-4) Resultados análisis EDX.

gráficas próximas a la torre (Lám. IIla). Si atendemos al caudal estacional típico de los arroyos o barranqueras que pasan cerca de la torre queda claro que en éstos se dan las condiciones favorables para la deposición de estos materiales. La frecuencia en que se encuentran junto a la buena clasificación de los áridos, en donde menos del 5\% de los granos presentan una fracción menor a las dominantes, hace plantear que la experiencia de los alarifes que construyeron la Torre de las Cabrerizas tuvo que ver mucho en este aspecto, mediante la criba de los sedimentos previo a su dosificación y amasado. 


\section{MATRIZ AGLOMERANTE}

Los aglomerantes son los componentes más finos utilizados para unir el conjunto de las partículas más gruesas (áridos) de manera que formen una masa coherente. Igualmente este componente dota a la mezcla, de capacidad para endurecer haciéndola manipulable y plastificante.

La matriz aglomerante documentada en la muestra presenta una granulometría dominada (50\%) por partículas dentro de las fracciones de tamaño "arena muy fina" (0.05-0.1 $\mathrm{mm}$ ) y "arena fina" (0.1-0.2 mm) incluidos en una micromasa fundamentalmente limosa. En SEM-EDX se caracteriza por presentar una composición química basada principalmente en calcio (Ca) y sílice (Si), en distintas proporciones, asociados a componentes basados en aluminio (Al), hierro (Fe) y potasio (K) (Lám. IIId.4). Mientras que los componentes de calcio se pueden asociar directamente a la utilización de la cal como elemento principal en la elaboración de la mezcla, producción ampliamente conocida durante época medieval (SEBASTIÁN y CULTRONE 2010; MARTÍN CIVANTOS 2007; RODRÍGUEZ GORDILLO 2005; MALPICA CUELLO 1998; VALVARDE ESPINOSA et alii, 1997), la presencia de silicio (Si), aluminio (Al) y hierro (Fe) nos hablan claramente del añadido de cierta proporción de arcillas y/o limos. Por otro lado, la presencia de sílices también se puede relacionar con la presencia de cuarzos dentro de las fracciones de tamaño "arena fina".

Gracias a la aplicación de la mezcla en estado fresco sobre el soporte los áridos quedaron moderadamente orientados paralelos al paramento y en una distribución relacionada de tipo cerrada o de simple espacio, hecho que se discutirá en el apartado siguiente.

\section{DOSIFICACIÓN Y MICROESTRUCTURA}

La calidad de los morteros se encuentra determinada por la naturaleza de la materia prima, es en la dosificación o en las proporciones en que se han mezclado áridos y aglomerantes donde se garantiza la aplicabilidad de la mezcla, su adherencia satisfactoria al soporte y el buen fragüe del mortero. De la misma manera y, junto a la calidad de la pasta aglomerante, le confiere al mortero propiedades físicas y mecánicas idóneas en las que la resistencia a la flexión y compresión son las propias, además de dotarle la capacidad de absorción y retención de agua controlable en el producto final.

Los morteros de revestimientos ricos en áridos utilizados en la construcción de la torre fueron elaborados mezclando dos a tres partes de gravas y arenas por cada parte de la pasta aglomerante hecha a base de cal, barro (limos y arcillas) y arenas muy finas (2.3:1 - 3:1). Aunque las mezclas muy ricas en áridos podrían disgregarse en estado fresco y no tendrían resistencia suficiente en estado endurecido, la pasta aglomerante a base de cal logró dar una buena cohesión a la mezcla durante el proceso de fragüe, hecho que queda evidenciado en la microestructura masiva y de escasa porosidad (2.48\%) (Lám. IIIb) que se puede observar en la muestra estudiada bajo lupa binocular. En este sentido los componentes más gruesos se encuentran incluidos en una micromasa intensiva dentro de la cual los granos se encuentran en contacto entre sí.

Estos hechos son evidencias también del proceso de amasado con cierta proporción de agua en las mezclas antes de su aplicación. Durante el amasado, que seguramente se realizó a pie de obra, se remueve el aire atrapado en la mezcla permitiendo así que durante el fragüe la microestructura de la misma se torne fuerte y evite la retracción excesiva del mortero y la formación de grietas.

Al tratarse de morteros de revestimientos aplicados sobre paramentos exteriores queda claro que los maestros de obra lograron una mezcla idónea en la que aseguraron no sólo una buena protección de la fábrica sino un mortero de excelente durabilidad. El que se conserven hasta el momento sobre los paramentos de la Torre de las Cabrerizas, al igual que en la del Espinar, se debe a la calidad de los mismos. Al igual que en otras torres como Cortijuelo, Anillos, Guzmanes y Sol. 


\section{Enlucidos}

Los enlucidos son mezclas finas que se aplican sobre los morteros de revestimiento más gruesos o enfoscados con los que se aporta un nuevo elemento en contra de los agentes de alteración externos y que confieren a la fábrica un sentido estético, además del funcional evitando la escalada a través de los paramentos. Durante Época Medieval en Andalucía se conoce ampliamente su uso, documentándose la utilización de enlucidos de cal, yeso o de cal y yeso (bastardos) en numerosas construcciones y edificios tanto en forma de acabados como en la elaboración de complejos elementos decorativos (SEBASTIÁN y CULTRONE 2010; MARTÍN CIVANTOS 2007; RODRÍGUEZ GORDILLO 2005; MALPICA CUELLO 1998b; VALVARDE ESPINOSA et alii, 1997). En nuestro caso, en la construcción de la Torre de las Cabrerizas como en la del Espinar, gran parte de las gruesas capa de enlucido se conservan en los paramentos exteriores y sobre todo, en el interior macizo de las estructuras, como vemos en las lechadas de cal de unión entre los mampuestos en la torres de las Cabrerizas.

\section{FORMAS DE ELABORACIÓN Y PUESTA EN OBRA}

En el análisis de la muestra de enlucido en SEM-EDX se caracteriza por una composición química dominada por la presencia de calcio (Ca), oxígeno (O) y un pico secundario de silicio (Si) (Lám. IVc.1 y Lám. IVd.4). Mientras que, como abordamos anteriormente, la presencia de calcio se puede relacionar directamente con la utilización de cal $\left(\mathrm{CaO}_{3}\right)$ en la manufactura de los enlucidos de la torre, en este caso la presencia de un pico secundario de silicio (Si) se debe asociar al empleo de una cierta proporción de cuarzos dentro de las fracciones "arenas muy finas" (20-100 $\mu \mathrm{m})$. De la misma forma se puede interpretar por la presencia de cuarzo en análisis de Difracción de Rayos X hechos a enlucidos procedentes de otras construcciones medievales en Andalucía (FERRER MORALES, 1996). En algunas zonas, muy localizadas, se han podido detectar agregados de naturaleza arcillosa, que en el análisis SEM-EDX se caracterizan por presentar una química basada en potasio (K), silicio
(Si), aluminio (Al), magnesio (Mg) y hierro (Fe), agregados que debieron quedar incluidos en la mezcla durante el proceso de manufactura (Lám. IV d3).

La escasez en componentes basados en aluminio (Al) o potasio (K), junto a otros elementos característicos de los minerales tipo filosilicatos, hace pensar en la intencionalidad de los alarifes en conseguir ciertas propiedades, si atendemos al hecho de que una mezcla basada en arcillas representaría un material de difícil aplicabilidad y adherencia al soporte. Podemos pensar que el nivel de experiencia permitió el establecimiento de un sistema de producción que garantizó la buena calidad de estos materiales, por ejemplo la mezcla de cal y arena muy fina (cuarzos).

No obstante, dentro de esta mezcla se ha documentado un fragmento de roca de naturaleza calcárea de tamaño "grava gruesa" (69 × 32 mm), (Lám. IV. 5a), el cual ocupa 5\% del área total de la muestra estudiada. Este componente puede tratarse de un fragmento de caliza que no se llegó a calcinar completamente durante la manufactura de la cal y que, debido a que se trata de un elemento aislado en la muestra estudiada, pudo quedar casualmente incluido en la mezcla durante el proceso de apagado y amasado de la misma.

\section{MICROESTRUCTURA Y PATRÓN DE HUECOS}

La microestructura es normalmente masiva y muy compacta (Lám. IV 5a), sin embargo en la muestra estudiada se observa que se encuentra algo rota por grietas y canales (porosidad 6.69\%), (Lám. IVb) asociados a la puesta en obra de la mezcla, aunque también a su exposición a la intemperie durante el tiempo. Las grietas se encuentran en gran parte directamente asociadas al fragmento de roca más grueso que quedó incluida en la mezcla, lo que pudo haber incidido en el agrietamiento del enlucido durante el fragüe.

Por su parte, los canales se pueden interpretar como ejemplos de bioturbación, que posiblemente incidieron en las grietas después del abandono de la torre y durante el 

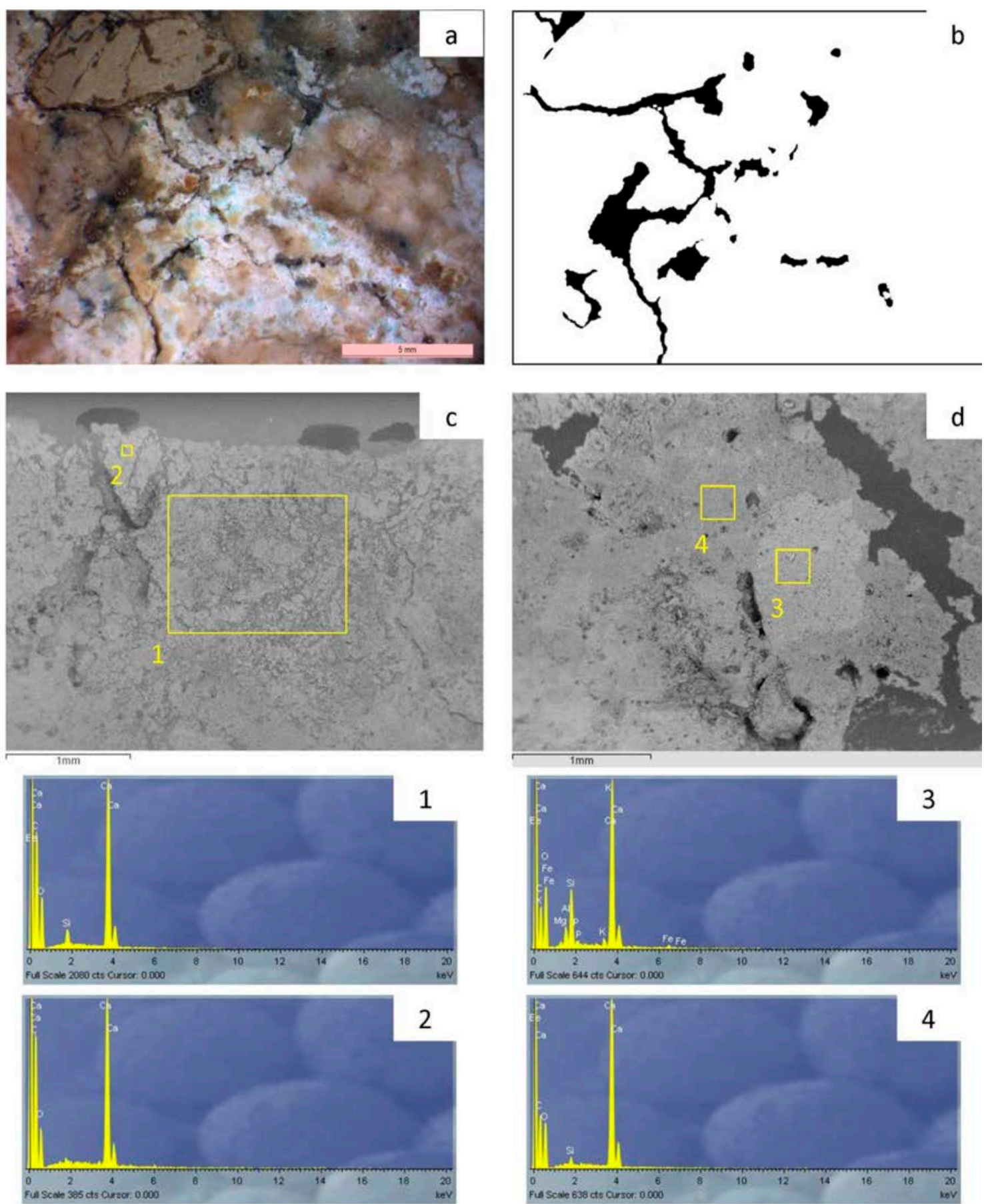

Lám. IV. Muestras de enlucido. a) Imagen tomada con lupa binocular; b) Resultado de análisis de imagen, porosidad; c-d) Imagen SEM; 1-4) Resultados análisis EDX.

paso del tiempo. Hay que tener en cuenta, que éstos enlucidos fueron destinados a dar acabado al paramento exterior de la torre, de ahí su grosor, por lo que el logro de una matriz fundamentalmente compacta y de escaza porosidad resultó ser un material eficiente en la protección de la fábrica ante los agentes de alteración externos.

\section{CONSIDERACIONES FINALES}

El hecho de que los materiales empleados en la elaboración de los morteros de revestimientos de la Torre de las Cabrerizas corresponden a aquellos encontrados en el entorno más próximo, hecho que puede ser interpretado como la intensificación en la 
explotación de los recursos minerales locales asociada directamente a la disponibilidad y cercanía de las zonas de extracción de la materia prima al lugar de la obra. Sin embargo, si se acepta, la naturaleza aluvial de los áridos hay que pensar en el esfuerzo que supondría el transporte de los mismos hasta el lugar de la construcción, lo que implicaría la utilización de medios de transporte idóneos para subir estos materiales hasta la torre, a través de las laderas que forman el cerro donde se ubica.

Los procesos de elaboración de los morteros de revestimiento empleados en el acabado exterior de la Torre de las Cabrerizas se fundamentan en el conocimiento de las propiedades físicas y mecánicas buscadas a la hora de su manufactura. Esta producción implica el conocimiento de las características idóneas de la materia prima para estos fines en función de su naturaleza y cualidades -elaboración y ejecución de la mezcla, resistencia a la compresión y flexión-, y el objetivo de cumplir satisfactoriamente las condiciones de solidez, aptitud y estética.

En relación a los morteros y enlucidos podemos deducir a través de las observaciones arqueológicas y las muestras analizadas una serie de correlaciones. En cuanto a los morteros de revestimiento compuestos fundamentalmente por áridos, aglomerantes o aditivos y agua. En relación a los áridos o arenas se componen de calcitas, dolomías, cuarzos y rocas detríticas fundamentalmente margas y calcarenitas, siendo en este tipo de morteros los áridos más gruesos. En el caso de los aditivos o conglomerantes, éstos son minerales y se componen de, Calcio, Sílicio, Aluminio, Hierro y Potasio siendo los cuarzos arenas finas o limos. La dosis observada a través de la muestra, es de 3 partes de arenas y gravas, 1 parte de cal y 2 partes de barro (limos y arcillas) y arenas muy finas.

En relación a los enlucidos, históricamente han sido de barro, cal, yeso, o bastardos. En la muestra analizada, se observa una composición de Calcio (cal), Oxígeno, Sílice siendo la arena. Los aditivos presentes se caracterizan por una naturaleza arcillosa, siendo diversos,
Potasio, Aluminio, Hierro, sílice, Magnesio todos ellos añadidos por los alarifes a la hora de realizar la mezcla de mortero usada en el enlucido que recubre las estructuras militares estudiadas.

La producción y uso de la cal en la elaboración de los morteros de revestimiento y enlucido implicó un alto nivel de organización en la que debieron participar un buen número de obreros y alarifes. Ésta debió estar distribuida por tareas, por ejemplo mientras que una parte se encargaba de la selección y transporte de la materia prima al lugar de la construcción, otro grupo se encargaría exclusivamente de la producción de la cal. Este hecho correspondería con la especialización del trabajo, según el nivel de conocimiento y experiencia que cada persona del grupo tendría dentro de cada etapa de la producción.

La obtención de mortero utilizado en la construcción de la Torre de las Cabrerizas, y en otras, compuesto por cal, pensamos que estaría relacionado con algunos de los topónimos conservados en Montefrío, como Las Galeras, Barranco de las Caleras, Fuente de la Calera o Arroyo de las Caleras (JIMÉNEZZ COMINO, 2009) situadas al NE y SE de la propia ubicación de la atalaya de las Cabrerizas, en dirección a Alcalá la Real. La cercanía a la obra de estos lugares junto a las características geológicas que dominan los entornos, hace que dichos lugares sean idóneos para el desarrollo de esta producción. Por tal razón entendemos que la realización de prospecciones arqueológicas sistemáticas podría aportar información acerca de estos temas, si tenemos en cuenta los posibles restos de esta producción, estructuras u hornos para la fabricación de la cal, canteras de aprovisionamiento, etc. Para éste argumento, contamos con información recogida en el Libro de Apeo (1581), concretamente referente a la existencia de un horno de cal en la senda del Perro al O de la Torre del Sol (JIMÉNEZ COMINO, 2009).

Aparte de las referencias toponímicas, encontramos referencias históricas, sobre la existencia de caleras, en un documento conservado en el Archivo de Protocolos de 
Montefrío, que dice así, "En fecha de 5 de Abril del año 1565, Diego Ponce, se obliga con los representantes de la Iglesia de la Villa, a traer sesenta cahices de cal, de la piedra del Hachuelo, que han de pagárselos al precio de siete reales cada uno, para ser empleados en la obra de esta Iglesia" (PÉREZ-VALENZUELA VALENZUELA 2007: 158), lo que nos lleva a plantear, que en el entorno de la torre del Hachuelo pudiera existir una cantera de cal ya desde antiguo, quizás en el período nazarí.

A mediados del siglo pasado existía en la zona de los Hundieros, a escasos metros del núcleo de Montefrío, una zona de producción de cal, utilizada como cantera o calera, lo que podría conllevar la posibilidad de que existiera algún horno de cal en sus inmediaciones.

Todas estas noticias nos llevan a pensar que la fabricación de cal, al igual que la de yeso o carbón realizada en el siglo XX, podría tener lugar en los mismos lugares donde se localizaban los afloramientos o vetas de materia prima necesaria para su elaboración, ¿no podría haberse obtenido la cal de la misma manera en lugares próximos a la construcción? En el caso de la construcción de atalayas, si tenemos en cuenta la ubicación de las mismas, los materiales de construcción, andamiajes y los materiales empleados en la elaboración de los morteros, solían proceder de los entornos de las propias atalayas y de los pequeños cursos fluviales cercanos. En el caso de la cal, podría proceder de los propios afloramientos de calizas tan característicos en la zona de Montefrío.

Hace poco ha surgido una publicación, en la que se mencionan los diversos oficios que existían en Montefrío entre 1950-1960, siendo la presencia de la cal frecuente y abundante, existiendo distintos vecinos dedicados a la obtención y a la venta de la misma (GUZMAN FLORES, 2010:25). Al igual que ocurre con los caleros, tenemos el ejemplo recogido por Guzmán Flores, en relación a la producción de carbón vegetal y su cocción y venta, a la que se dedicaban gran cantidad de vecinos de Montefrío (GUZMAN FLORES, 2010:25).
Oficios tradicionales, que se solían hacer a pie de cantera, reduciendo el coste tanto humano como económico en la obtención de dichos productos como podrían ser la cal, el carbón, el yeso, etc. Por tanto, habría que prestar más atención al entorno inmediato de dichas construcciones, canteras, etc., para documentar las posibles explotaciones dedicadas a la cal, piedra, minerales, etc., y otras fuentes de aprovisionamiento, como agua y madera utilizada en la construcción de atalayas, poblados y necrópolis, a lo largo de los distintos períodos históricos.

\section{BIBLIOGRAFÍA}

IBN Al-JAṬīB: (1978). Al-Ihāṭa fī ajbār Garnāṭa. Ed. 'Inan. El Cairo, t. IV.

ACIÉN ALMANSA, M. (1999): "Los tugur del reino nazarí. Ensayo de identificación”. Castrum, 5, Archéologie des espaces agraries mediterranées au Moyen Age. Murcia, pp.427-438.

SORIANO, C. (1993): Los hechos del Condestable don Miguel Lucas de Iranzo. Estudio y edición de C. Soriano. Madrid, Universidad Complutense.

Alawna, S. (2003): Las técnicas constructivas empleadas en los castillos de la frontera norte del Reino Nazarí de Granada. Tesis Doctoral. Inédita. Universidad de Granada.

ÁLVAREZ GALINDO, J. I; MARTín PÉREZ, A; GARCÍA CASADO, P. J., (1995): "Historia de los morteros". PH Boletín 13. pp. 52-57.

ÁLVAREZ GALINDO, J. I. y ONTIVEROS ORTGA, E., (2006): "Morteros" en PH cuadernos 19: Programa de normalización de estudios previos aplicado a bienes inmuebles. Instituto Andaluz de Patrimonio Histórico, Consejería de Cultura de la Junta de Andalucía, Sevilla: pp. 92-144.

ARGÜELLES MÁRQUEZ, M., (1987): "El sistema defensivo nazarí Montefrío-Moclín”. Congreso Arqueología Medieval Española, t. II. Madrid, pp. 85-91.

ARGÜELLES MÁRQUEZ, M., (1995): "Sistema de vigilancia y control del Reino Nazarí en Granada”, Arqueología y territorio Medieval. № 2. Jaén, pp. 83-97.

BELLÓN AGUILERA, J., PEDREGOSA MEGÍAS, R. J. (2004): "En la Frontera del Reino de Granada: una intervención arqueológica en las torres-atalayas de Montefrío". Antiqvitas 16, Córdoba, pp. 121-129.

BELLÓN AGUILERA, J., PEDREGOSA MEGÍAS, R. J., (2010): "Intervención arqueológica puntual "Torres-atalayas" de Montefrío (Granada). Anuario Arqueológico de Andalucía 2005. Sevilla. pp. 1529-1533.

BOSQUE MAUREL, J., FERRER RODRÍGUEZ, A. (1999): Granada: la tierra y sus hombres. Granada. 
BOSQUE MAUREL, J., FERRER RODRÍGUEZ, A., (2000): "Geografía del antiguo Reino de Granada", en Peinado Santaella, R. G. (ed.): Historia del Reino de Granada. I. De los orígenes a la época mudéjar (hasta 1502). Granada, Universidad de Granada-El legado andalusí, pp. 15-54.

CARRASCO, J., NAVARRETE, Ma. S., PACHÓN, J. A., PASTOR, M., GÁMIZ, J., ANÍBAL, C., TORO, I., (1986): El poblamiento antiguo en la tierra de Loja. Granada.

BORDES GARCÍA, S., (2001): "La frontera nazarí en el sector oriental de Loja: Íllora y Montefrío". En LÓPEZ LÓPEZ, M. (Ed.): La última frontera de al-Andalus. (Guía arqueológica del poniente granadino). Loja, pp. 55-75.

DE LUQUe MARTíneZ, F., (2003): El Castillo de Piñar: Análisis estratigráfico de las estructuras de superficie. Granada, Nakla.

ESLAVA GALÁN, J., (1984): "Materiales y técnicas constructivas en la fortificación bajomedieval”. Cuadernos de Estudios Medievales. VOL: XII-XIII, pp. 271-278.

FERRER MORALES, A., (1996): "Decoración de muros en castillos califales de Andalucía Oriental". En: Atrio. Revista de Historia del Arte, no. 8-9. Sevilla, pp.3-18.

GARCÍA-PULIDO, L. J., (2013): "El sistema constructivo empleado en la torre nazarí de Agicampe (Loja, Granada). En: Huerta, Santiago y Fabián López Ulloa (eds.). Actas del Octavo Congreso Nacional de Historia de la Construcción. Madrid, 9-12 de octubre de 2013. Madrid: Instituto Juan de Herrera. Volumen I, pp. 375-3.84.

GUZMÁN FLORES, J., (2010): Montefrío. Historia de sus vidas y sus gentes años 50 y 60. Granada.

JIMÉNEZ COMINO, F.: (2009). Procesos de revisión de tierras baldías. Apeos, composiciones y ventas 1581 (Inédito).

JIMÉNEZ MATA, Ma C., (1990): La Granada islámica. Chrónica Nova. Estudios Históricos, 10. Universidad de Granada. Diputación Provincial de Granada.

JIMÉNEZ PUERTAS, M., (2002): El poblamiento de Loja en la Edad Media. Chrónica Nova. Estudios Históricos, 77. Universidad de Granada. Granada.

LINARES PALMA, J., (1964): "El Castillo de Montefrío". Castillos de España no 44, pp. 15-42.

MADOZ, P., (1987): Diccionario geográfico-estadístico e histórico de España y sus posesiones de ultramar. (Ed.) facsímil, Madrid, pp. 538-542.

MALPICA CUELLO, A., (1996): Poblamiento y castillos en Granada. Granada.

MALPICA CUELLO, A., (1998a): "Los Castillos en época nazarí. Una primera aproximación”. En: Castillos y territorio en al-Andalus, Granada, pp. 246-293.

MALPICA CUELLO, A., (1998b): "Las técnicas constructivas en Al-Andalus. Un debate entre la Arqueología y la Arquitectura". En: Técnicas agrícolas, industriais e constructivas na Idade Media, pp. 277-336.

MALPICA CUELLO, A., (2003): Los Castillos en Al-Andalus y la organización del territorio. Cáceres. Universidad de Extremadura.
MARTIN GARCIA, M., (1996): "Torres atalayas de la provincia de Granada. Funciones, formas, materiales y criterios para su restauración". Alzada. VOL. 46. pp. 34-41.

MARTÍN GARCÍA, M., BLEDA PORTERO, J., MARTÍN CIVANTOS, J. M., (1999): Inventario de la arquitectura militar de la provincia de Granada (Siglos VIII al XVIII). Granada.

MARTÍN GARCÍA, M., MARTÍN CIVANTOS, J. M., (1998): "Torres Atalayas entre Alcalá La Real y el Reino Nazarí de Granada", Congreso Estudios de Frontera II Alcalá la Real. Jaén, pp. 481-519.

MARTÍN CIVANTOS, J. M., (2001-2002): “Ensayo de análisis comparativo de técnicas, materiales y tipos constructivos en las fortificaciones medievales del Zenete (Granada)". Miscelánea Medieval Murciana. Vol. XXV-XXVI, Murcia, pp. 183-220.

MARTÍN CIVANTOS, J. M., (2007): Poblamiento y territorio medieval en el Zenete (Granada). Universidad de Granada, Granada.

MARTÍNEZ LILLO, S., (1990): "Arquitectura militar de ámbito rural de la Marca Media (al-tagr al-awsat). El alfoz de Talabira: Antecedentes y evolución". Boletín de Arqueología Medieval, № 4, pp. 135-172.

ONIEVA MARIEGES, J. M., (1977): El municipio de Montefrío. Estudio geográfico. Granada, Universidad de Granada.

ONTIVEROS ORTEGA, E., (2001): "Programa de normalización de estudios previos y control de calidad en las intervenciones: morteros empleados en construcciones históricas. Formulación y características $2^{a}$ parte”. PH Boletín. № 35, pp. 69.77

PEDREGOSA MEGÍAS, R. J. (2007a): "Una posible intervención de Conservación-Restauración en la frontera noroccidental del Reino de Granada: Las torres-atalayas de Montefrío". VERDOLAY. № 10. Murcia, pp. 275-297.

PEDREGOSA MEGÍAS, R. J., (2007b): "Una intervención Arqueológica en la Torre-atalaya del Espinar, Montefrío (Granada) Antiqvitas, No 18-19, M.H.M. Priego de Córdoba, pp. 215-226.

PEDREGOSA MEGÍAS, R J., (2010a): Montefrío en Época Nazarí. Proyecto de Investigación para la obtención de D.E.A. Máster Oficial "Arqueología y Territorio". Universidad de Granada, Inédito.

PEDREGOSA MEGÍAS, R J., (2010b): "Intervención Arqueológica Puntual en la Torre-Atalaya del Espinar, Montefrío (Granada). Anuario Arqueológico de Andalucía, 2006 Sevilla, pp. 1294-1303.

PEDREGOSA MEGÍAS, R. J., (2011a): Guía históricaarqueológica del castillo y atalayas de Montefrío (Granada). Sevilla.

PEDREGOSA MEGÍAS, R. J., (2011b): "Montefrío en época nazarí”. Arqueología y Territorio no 8, pp. 187-205.

PEDREGOSA MEGÍAS, R. J., MARTíNEZ MARTíNEZ, C., (2014): "La evolución de la frontera en el sector Montefrío-illora-Moclín-Colomera y su relación con la vecina Alcalá la Real en época nazarí". Estudios de Frontera 9. Alcalá la Real, Jaén. Diputación provincial de Jaén e Instituto de Estudios Giennenses, pp. 535-555. 
PEINADO SANTAELLA, R. G., (1997): Montefrío 1752. Según las respuestas generales del Catastro de Ensenada. Madrid, Alcabala del viento, 75.

PÉREZ-VALENZUELA VALENZUELA, J., (2007): La Villa de Montefrío: su historia y sus gentes. Edita Ayto. Montefrío.

RODRÍGEZ GORDILLO, J. F., (2005): "Morteros como elementos de estudio en Arqueología-Arqueometría Medieval", en Arqueometría y Arqueología Medieval. Editorial Al-Baraka, Granada: pp. 171-192.

RUBIO CINTAS, A., MORENO RODA, J. H. (2006) "El sistema defensivo nazarí en la comarca de Baza. Torres atalayas de la comarca de Baza". Péndvlo, 7, pp. 49-92.

SALVATIERRA CUENCA, V., ARGÜELLES MÁRQUEZ, M., MORENO ONORATO, M. A., (1989): "Visibilidad y control: Un problema de fronteras. El caso Nazarí en el sector Montefrío-Moclín." Arqueología Espacial, 13, Teruel, pp. 229-240.
SARR, B., MATTEI, L. (2011): “De hisn a madina. La evolución del urbanismo en el surco intrabético: Guadix, Loja y otros espacios menores. Un estado de la cuestión". Espacio, Tiempo y Forma. Serie III Historia Medieval, 24, pp. 387-414.

SEBASTIÁN, E., CULTRONE, G., (2010): "Technology of Rammed-Earth Constructions ("Tapial") in Andalusia (Spain): Their Restoration and Conservation", Materials, Technologies and Practice in Historic Heritage Structures. Eds. Maria Bostenaru Dan, Richard PĜikry y Ákos Törö, New York, Springer: pp. 11-29.

SECO DE PAREDES, L., (1974): Topónimos árabes identificados. Granada.

VALVARDE ESPINOSA, I., ONTIVEROS ORTEGA, E., SEBASTIÁN PARDO, E., (1997): "El tapial en las murallas de Granada”. RE: revista de edificación, Vol. 26. Servicio de Publicaciones de la Universidad de Navarra: pp. 58-63. 